\title{
Gas Nitriding Behaviour of 34CrAlNi7 Nitriding Steel
}

\author{
I. Altinsoy ${ }^{a} *$, K.G. Onder ${ }^{b}$, F.G. Celebi Efe ${ }^{c}$ And C. Bindal ${ }^{a}$ \\ ${ }^{a}$ Sakarya University, Engineering Faculty, Department of Metallurgy and Materials Engineering \\ Esentepe Campus, Serdivan, Sakarya, Turkey \\ ${ }^{b}$ Mikrosan Makina ve Kalıp San, A.S. Heat Treatment Department, Izmit, Kocaeli, Turkey \\ ${ }^{c}$ Sakarya University, Karasu Vocational High School
}

\begin{abstract}
In this study, gas nitriding behavior of $34 \mathrm{CrAlNi}-10$ steel was investigated. Single stage processes were carried out at $500{ }^{\circ} \mathrm{C}, 520^{\circ} \mathrm{C}$ and $540{ }^{\circ} \mathrm{C}$ for $10,20,30 \mathrm{~h}$, respectively. Nitrogen activity on surface was controlled by the nitriding potential $K_{\mathrm{N}}$ which is known as thermodynamical control parameter for controlled gas nitriding process. The presence of nitrides formed on surface of test material was determined by X-ray diffraction analysis technique. The morphology of nitrided layer was studied by optical microscope. The microhardness of surface of nitrided sample in $\mathrm{HV}_{1}$ was observed between 975 and 1132. Choosing the right nitriding potentials for each temperature, which give the same nitrogen concentration and activity on surface by using the Lehrer diagram, showed that all the samples had almost the same surface roughness of $R_{\mathrm{a}}=0.28-0.32 \mu \mathrm{m}$ after gas nitriding cycles. The measurements showed that the white layer thickness varies between $4.38 \mu \mathrm{m}$ and $28.80 \mu \mathrm{m}$ and the growth of the layer was strongly affected by process time and temperature. Diffusion depths as Nht (HV) for each experiment were determined and compared.
\end{abstract}

DOI: $10.12693 /$ APhysPolA.125.414

PACS: 81.05.Bx, 81.65.Lp

\section{Introduction}

Gas nitriding is a thermochemical heat treatment process, whose high hardness, enhanced corrosion properties, and considerably improved wear resistance and fatigue strength are obtained on the material surface by diffusion of atomic nitrogen through the surface. Controlling the process by the thermodynamical parameter " $K_{\mathrm{N}}$ " gives ability to produce hardened layers that have variable metallurgical properties. It is possible to produce parts with improved surface properties and prolonged working life as a result of nitriding with right process parameters and proper material selection by taking into account the properties of operating environment, operating conditions and the mechanical requirements for the surface [1]. Time and temperature represent the main factors which determine the hardness profile on nitrided steels with certain composition [2]. 34CrAlNi7 is $\mathrm{Cr}-\mathrm{Al}-\mathrm{Ni}$ alloyed industrial nitriding steel widely used in manufacturing of machine elements where the high surface hardness and improved wear resistance is required. Binary and ternary alloys have been the subject of many investigations, which showed that aluminium and chromium increase nitrogen content and hardness, due to the chromium nitrides fcc semi-coherent precipitation. Nevertheless, mechanisms due to aluminium are not clear [3]. After such a treatment, generally a thin compound layer known as "white layer" consists of $\varepsilon$ and $\gamma^{\prime}$ iron nitrides together on the surface where aluminium enriched $\gamma^{\prime}$-phase of $(\mathrm{Fe}, \mathrm{Al})_{4} \mathrm{~N}$ lies below the $\varepsilon$-phase and

*corresponding author; e-mail: ialtinsoy@sakarya.edu.tr penetrates into the depth of the metal along grain boundaries [4].

The main objective of the present study is to investigate the gas nitriding behavior of $34 \mathrm{CrAlNi}$ steel by changing the process parameters and observe the effect of parameters on some properties of nitrided zone.

\section{Experimental study}

In this study; for the $34 \mathrm{CrAlNi} 7$ nitriding steel, one stage gas nitriding processes are performed via $K_{\mathrm{N}^{-}}$ -controlled gas nitriding method at 500,520 and $540{ }^{\circ} \mathrm{C}$ by $10,20,30 \mathrm{~h}$, respectively. Effect of parameters on mechanical properties of nitrided zone and its characteristic was investigated. According to the Lehrer diagram, $K_{\mathrm{N}}$-nitriding potentials was selected between 4.2

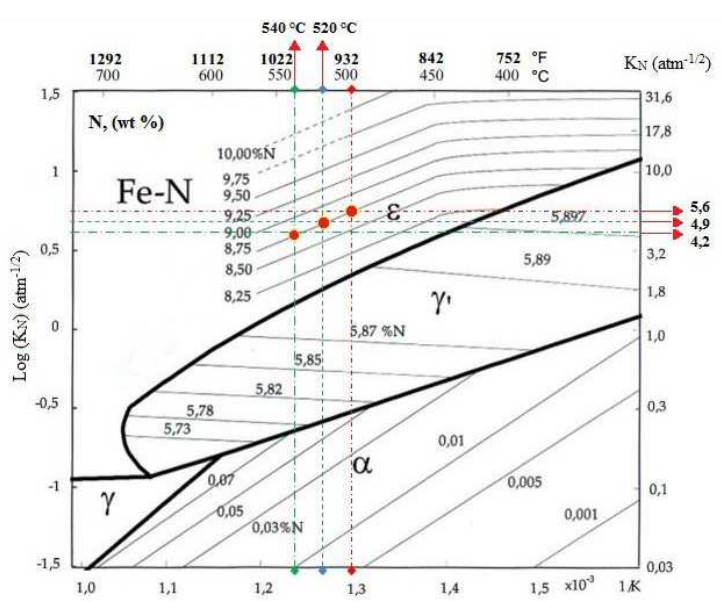

Fig. 1. Representation of gas nitriding parameters on the Lehrer diagram. 
and $5.4 \mathrm{~atm}^{-1 / 2}$ values which provide the same nitrogen concentration on surface at selected temperatures (Fig. 1) [5]. Nitriding depths were determined by measuring microhardnesses on diffusion zone. Surface hardnesses were measured by using $\mathrm{HV}$ hardness method. Microstructure pictures of the nitrided zones were taken by using light-metal microscope and the thickness of the white layer and diffusion zones were measured by using Clemex software. The XRD analysis of the surfaces were made and the phases in the white layer were determined. The surface roughness of $R_{\mathrm{a}}$ was measured by profilometer on five different areas having dimensions of $0.8 \mathrm{~mm} \times 5$.

\section{Results and discussions}

As it can be seen from Fig. 2, optical micrographs of the nitrided zones reveal that white layer grows by increasing temperature and time but the growth and structure of the layer differs from the other industrial steels that contain no aluminium. Aluminium promotes intercrystalline diffusion of nitrogen and alloys the $\gamma^{\prime}$-phase in form of $(\mathrm{Fe}, \mathrm{Al}){ }_{4} \mathrm{~N}$. In addition to that, $\gamma^{\prime}$ phase grows preferentially in the "whiskers" form through the grain boundaries and slip planes $[4,6]$.

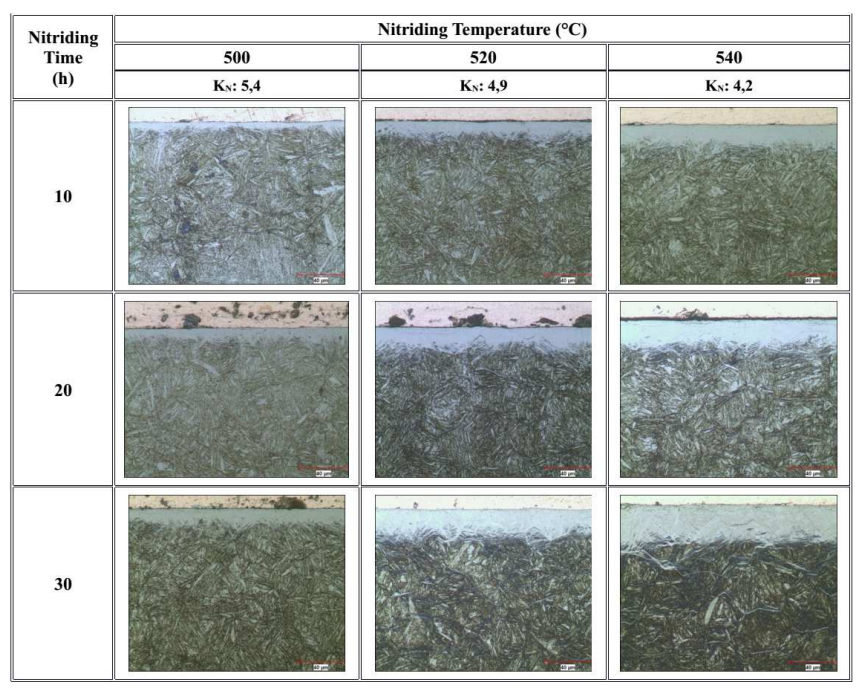

Fig. 2. Optical microscope images of the $34 \mathrm{CrAlNi} 7$ samples gas nitrided at different temperatures for 10 , 20 and $30 \mathrm{~h}(500 \times)$.

Figure 3 shows that the XRD patterns for samples were gas nitrided at $500{ }^{\circ} \mathrm{C}$ and $540^{\circ} \mathrm{C}$ for different times. Results reveal that by choosing the nitriding potential in $\varepsilon$-phase region according to the Lehrer diagram, the compound layer consists of $\varepsilon-\gamma^{\prime}$ phases together and occurs in bilayer structure. Potentials were chosen, induce the white layer growth in bilayer form and provide the phases to be predominantly in $\varepsilon$-nitrides. Increase in the intensity of the peaks by raising process time and much increase in $\varepsilon$-phase peaks against $\gamma^{\prime}$-phase, confirm the approach.
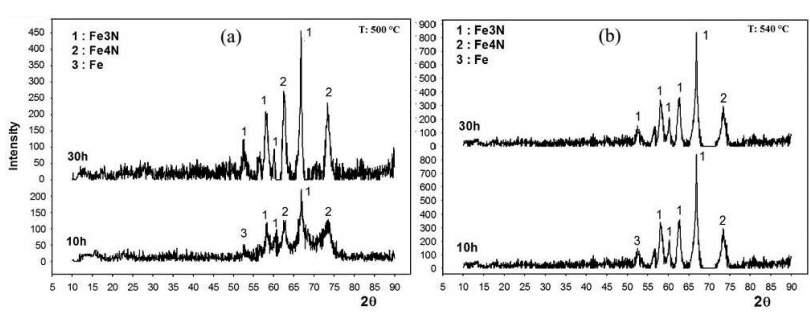

Fig. 3. XRD patterns of samples 10 and $30 \mathrm{~h}$ gas nitrided at $500{ }^{\circ} \mathrm{C}$ and $540{ }^{\circ} \mathrm{C}$.

Average results of the measurements for compound layers were shown in Fig. 4. By taking into account the Lehrer diagram, the values for the nitriding potentials keep the same nitrogen activity on the surface for each process temperature and stabilize the wt\% N content of the $\varepsilon$ phase. Results reveal that white layer thickness of $34 \mathrm{CrAlNi} 7$ steel increases by increasing temperature and time for the same nitrogen activity on the surface.

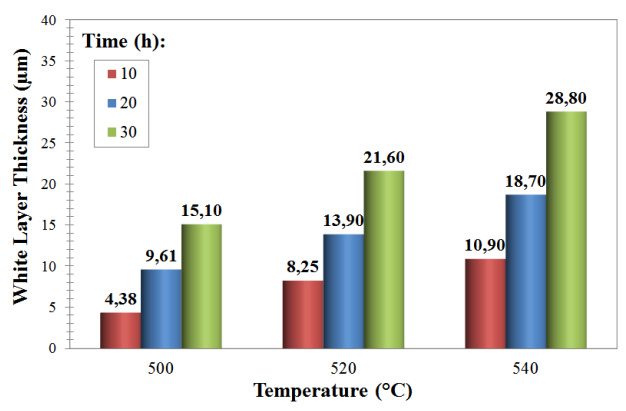

Fig. 4. White layer thicknesses in single stage gas nitrided $34 \mathrm{CrAlNi} 7$ steel.

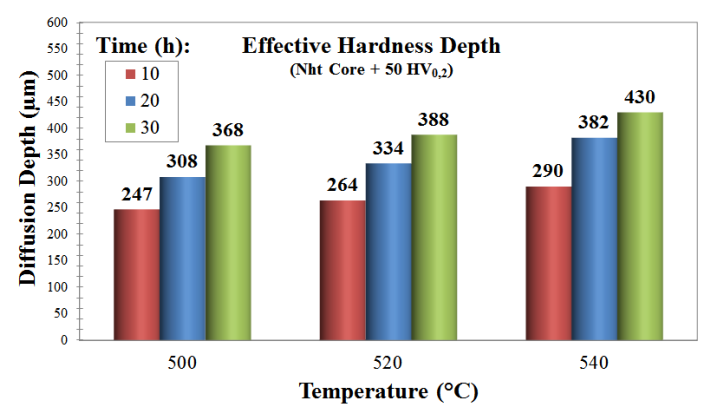

Fig. 5. Effect of time and temperature on effective hardness depth Nht (Core Hardness $+50 \mathrm{HV}_{0.2}$ ) of $34 \mathrm{CrAlNi} 7$ steel.

Figure 5 shows that the diffusion depth increases by increasing time and temperature. The results are consistent with the literature and diffusion equations. Increasing time provides more atomic nitrogen diffusion towards the core while increasing temperature raises the diffusion coefficient of nitrogen and provides the same effect. 


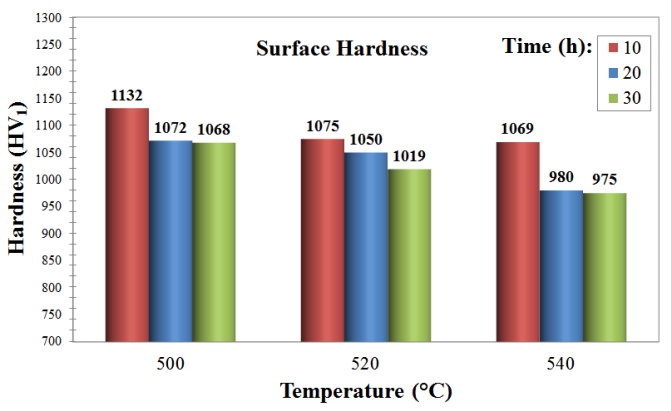

Fig. 6. Effect of time and temperature on surface hardness of $34 \mathrm{CrAlNi} 7$ steel.

Figure 6 shows the average values of $\mathrm{HV}_{1}$ surface hardnesses. The hardness values decrease by increasing process temperature and time. The decrease in surface hardness seems more associated with the white layer thickness. Because of the fact that the increase in the white layer thickness makes the compound layer more brittle, the $\mathrm{HV}_{1}$ hardness decrease in addition to brittleness increase. The cracks in the thicker white layers are seen in Fig. 2 and similar hardness results for similar white layer thicknesses regardless the process temperature and time, verify the approach.

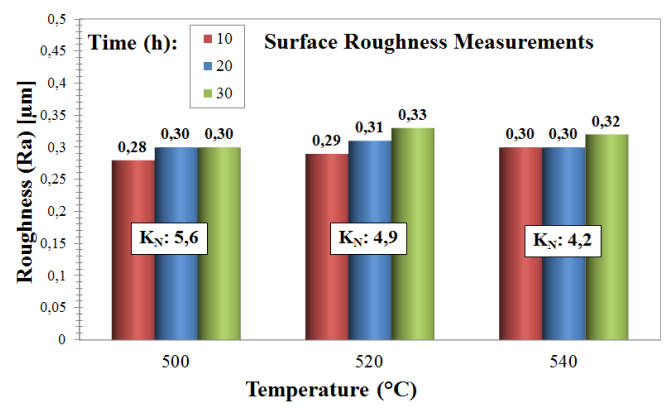

Fig. 7. Effect of time, temperature and nitriding potential on surface roughness of $34 \mathrm{CrAlNi} 7$ steel.
Surface roughness results reveal that by selecting the right nitriding potential for each process temperature, it is possible to reach very similar surface roughness values on surface (Fig. 7). Because of the fact that the nitriding potentials stabilize the wt $\% \mathrm{~N}$ content for $\varepsilon$-phase and the surface roughness is related with the wt\% $\mathrm{N}$ content of white layer $[1,7]$, the experimental results are consistent with the literature. Slight increase in the roughness is related with increase in the white layer thickness because of the temperature and time.

\section{References}

[1] K. Önder, M.Sc. Thesis, T.C. Sakarya Üniversity, 2013.

[2] R. Schneider, H. Hiebler, J. Mater. Sci. 33, 1737 (1998).

[3] C. Ginter, L. Torchane, J. Dulcy, M. Gantois, A. Malchere, C. Esnouf, T. Turpin, La Metallurgia Italiana 7-8, 29 (2006).

[4] Y. Lakhtin, Metal Sci. Heat Treatm. 38, 6 (1996).

[5] M. Korwin, W. Liliental, L. Maldzinski, A. Czelusniak, G. Tymowski, Nitreg Controlled Gas Nitriding an Enviroment-Friendly Process for Surface Hardening of Steel, Nitrex Metal Inc., Canada 1999.

[6] Y. Lakhtin, N. Silina, V. Fedchun, Nature of the High Hardness and Brittleness of the Nitrided Case on Steel 38Kh2MYuA, Plenum Publishing Corporation, 1981, p. 162.

[7] S. Hosmani, R. Schacherl, E. Mittemeijer, Compound Layer Formation on Iron Based Alloys upon Nitriding; Phase Consitution and Pore Formation, Carl Hanser Verlag, HTM, München 2008, p. 139. 